\title{
DIAGRAM ARSITEKTUR
}

\author{
Denny Husin ${ }^{1}$ \\ ${ }^{1}$ Jurusan Teknik Arsitektur, Universitas Tarumanagara Jakarta \\ denny_husin@yahoo.com
}

\begin{abstract}
ABSTRAK
Kompetisi arsitektur menuntut penggambaran arsitektur untuk berbenah dan tetap berinovasi dalam mendapatkan perhatian dan menghasilkan kualitas karya arsitektur terdepan. Kepiawaian arsitek, kemajuan teknologi, dan kecepatan intelektual dalam menghasilkan karya arsitektur, haruslah beriringan dengan peran penting khazanah keberagaman penggambaran arsitektur. Kompetisi penggambaran Arsitektur menuai problema dengan semakin besarnya proporsi dan komposisi dekorasi dan hiasan dalam penggambaran untuk menarik perhatian penggunanya daripada berkonsentrasi pada elemen fundamental gambar aristektur. Esensi penggambaran arsitektur ditelaah kembali dalam tulisan ini dengan menelusuri rekam jejak melalui etimologi frase diagram arsitektur, sebagai instrumen fundamental dalam membahasakan ruang. Metode kualitatif dengan pemikiran konstruktif digunakan untuk menhasilkan sebuah uraian yang, menjabarkan, menjelaskan dan menyajikan makna sebenarnya dari diagram arsitektur, serta mengangkat permasalahan teraktual termasuk menawarkan sebuah alternatif solusi dengan mengedepankan esensi. Melalui studi kepustakaan, paradigma penggambaran arsitektur dipertanyakan, khususnya peran dan aplikasi diagram dalam sebuah karya tulis ilmiah.
\end{abstract}

Kata kunci: arsitektur, diagram, paradigma.

\section{PENDAHULUAN}

Diagram arsitektur adalah bahasa gambar yang digunakan dalam bidang arsitektur untuk menerangkan konsep, prinsip, anasir, dan komponen, termasuk cara kerja maupun petunjuk penggunaannya. Secara profesional, arsitek tidak bekerja sendirian, tetapi bekerja dengan memproduksi diagram yang digunakan dalam menerangkan ide dan pemikirannya dalam perwujudan sketsa yang bersifat skematis (Pai, 2002). Kemudian, diagram tersebut pada praktiknya akan dilanjutkan oleh asisten, 3D artis, drafter sampai kepada pembuat maket untuk diwujudkan baik dalam bentuk gambar kerja, detail atau bahkan gambar - gambar presentasi. Diagram secara kebahasaan diterjemahkan sebagai gambar grafis sederhana yang menunjukkan tampilan, struktur, cara kerja maupun tampilan skematis (Stevenson,2010). Namun demikian kompetisi dalam ranah arsitektur menempatkan diagram dalam situasi yang menuntut penggambaran menjadi kompleks dan mengikuti perkembangan jaman, sayangnya pengembangan ini seringkali jatuh pada elaborasi daripada pengembangan esensi dari diagram sebagai gambar arsitektural. Untuk memberikan pemahaman tentang penggambaran diagramatik, baiknya kita menilik kembali arti sesungguhnya melalui tinjauan etimologi.

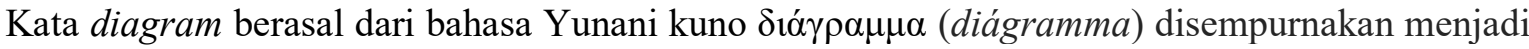
dia: melalui, dan graphein diagraphein yakni menandai melalui garis. Kata ini digunakan dalam bahasa latin diagramma dan bahasa Perancis diagramme sejak tahun 1610 (Onions, 1966). Peran diagram menjadi kompleks pada penggunaannya sesuai dengan penjelasan Stevenson dalam Oxford English Dictionary melalui deskripsi perwujudan jenis diagram: berupa bilangan maupun kerangka sebagai bukti tambahan sebuah proposisi; menjadi ilustrasi tubuh sebuah objek yang menerangkan siluet atau skema umum sehingga dapat menerangkan bentukan dan hubungan anasir objek yang dijelaskan; memungkinkan terbentuknya sebuah kepaduan garis, tanda, jejak yang mewakili secara simbolik arahan maupun hasil dari sebuah aksi, proses termasuk variasi karakter yang dihasilkan; berbentuk daftar, rekaman maupun perhitungan; lainnya dalam kaitan dengan musik menjadi paranada. Diagram dapat pula mendeskripsikan media khusus dalam ranah tertentu. Dari kategori diatas, diagram dijelaskan sebagai media gambar yang memiliki potensi untuk digunakan dalam eksplorasi, deskripsi, analisa, penerangan, penjelasan maupun 
pembedahan; sebuah alat yang berpeluang mengungkapkan realitas tersembunyi (Allen,1999) baik prinsip maupun masalah dari sebuah objek khususnya tapak dalam arsitektur. Dengan demikian, diagram menjadi esensial tidak hanya untuk mendeskripsikan sebuah rancangan namun dalam proses mengembangkan sebuah rancangan (Pai, 2002). Kesederhanaan dan kelugasan diagram menjadi kontras bila kita sandingkan dengan tuntutan kompetisi ranah arsitektur yang sibuk berlomba - lomba menarik simpati, memanipulasi dan merias gambar arsitektur secara kompleks melalui dekorasi dan ilusi perspektif.

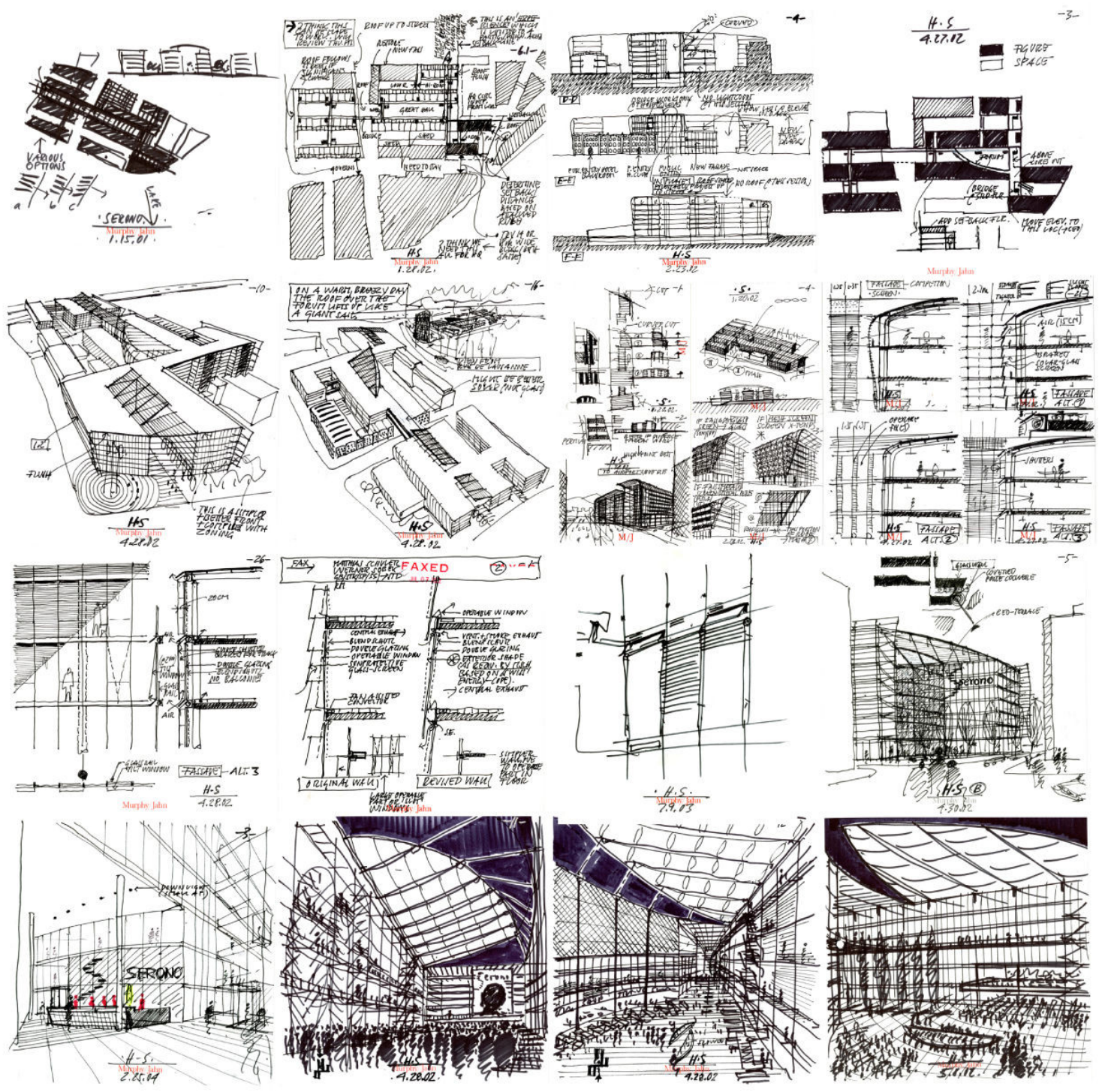

Gambar 1. Merck Sereno Headquarters Murphy Jahn

Sumber : http://www.archdaily.com/231602/flashback-merck-sereno-headquartersmurphyjahn/503828ee28ba0d599b001185-flashback-merck-sereno-headquarters-murphyjahn-sketch 


\section{RUMUSAN MASALAH}

Diagram arsitektur sebagai alat penggambaran primitif awalnya digunakan secara khusus untuk menerangkan rancangan sebuah bangunan, yakni untuk mengkomunikasikan penjelasan objek (Dulić, 2016) yang akan dibangun kepada tukang. Hal ini dapat ditelusuri melalui rekam jejak arti dari arsitektur sendiri yang merujuk kepada arsitek sebagai profesi daripada arsitektur sebagai objek bangunan (Onions, 1966). Secara etimologi arsitektur berasal dari kata berbahasa Yunani $\alpha \rho \chi \imath \varepsilon \dot{\kappa} \kappa \omega \nu$ (arkhitéktōn, "architect" terdiri dari kata arkhi: kepala, tekton: tukang) yang mengacu kepada kepala tukang, sebelum berkembang sebagai kata berbahasa latin architectus, kata berbahasa Perancis dimulai penggunaanya pada tahun 1550 (Onions, 1966) dan heahcroeftiga, kata berbahasa Ingris kuno yang berarti tukang dengan kepiawaian tinggi (Stevenson, 2007). Diagram awalnya ditujukan sebagai gambar kerja yang ditujukan kepada tukang untuk membuat sebuah objek arsitektural, penggambarannya dikerjakan oleh kepala tukang, tukang yang memiliki kelebihan, seorang dengan tingkat intelektual tinggi berkenaan dengan bangunan dan/atau seorang kontraktor sehingga tukang mengerti dan mengimplementasikannya menjadi objek arsitektural. Kompleksitas arsitektur menuntut kompetisi dalam inovasi dan kreativitas. Dalam pengejewantahannya, arsitektur ditampilkan melalui penggambaran baik dalam dua, tiga, empat dimensi dan seterusnya (Einsenman, 1999). Dalam kompetisi yang ketat ini penggambaran arsitektur mengembangkan dirinya bersamaan dengan perluasan maupun pembagian tugas profesi arsitek.

Penggambaran mengembang dan mengempis sesuai dengan diversifikasi dan spesifikasi dari setiap penugasan dalam kegiatan arsitektural. Penugasan klien kepada kepala tukang untuk membangun sebuah arsitektur kini dilakukan melalui jalur dalam jejaring berjenjang yang panjang dan berliku demi menghasilkan keabsahan dan kualitas detail berasaskan pedoman dan arahan standarisasi ranah arsitektur. Kesederhanaan diagram dengan tujuan aplikasi langsung telah mengalami sebuah evolusi dan pemalihan (transformation) baik secara intelektual maupun teknologikal (Pai, 2002). Diagram kini diperjual-belikan sebagai lukisan mahakarya yang dihias dengan warna dan pelbagai keruwetannya (Graf, 2007). Diagram tidak lagi bersifat statis datarpersegi, tapi telah bertransformasi membentuk jejaring berkas yang beralih arsip lintas dimensi. Bahkan, kini diagram dikerjakan dalam sebuah pemetaan digital, lokal dan global melalui jaringan matriks dengan metode parametris yang memastikan ketepatan ukuran (Pyo, 2011). Kompleksitas ini kerap kali menjadi bias, bersifat ilusional dan hanya berada di permukaan ketika dihadapkan kepada awam yang berfokus pada keindahan dan kerumitan visual sebuah objek representatif. Diagram yang sebelumnya dikategorikan sebagai gambar kerja arsitektur pada masa lampau kini diasosisasikan sebagai gambar representatif visual (Pyo 2012), sebagai kontras batas perbedaan antara diagram, sketsa, gambar kerja, perspektif dan gambar - gambar arsitektural menjadi kabur dan dimaknai dengan label yang sama yakni diagram arsitektur. Warna, tektur, sudut pandang, termasuk hiasan berupa dekorasi dan ornamen masih menjadi pilihan utama untuk meramaikan gambar arsitektur, menjadi pemanis, penyeimbang proporsi dan komposisi termasuk menutupi kecacatan dari rancangan sebuah objek arsitektur. 

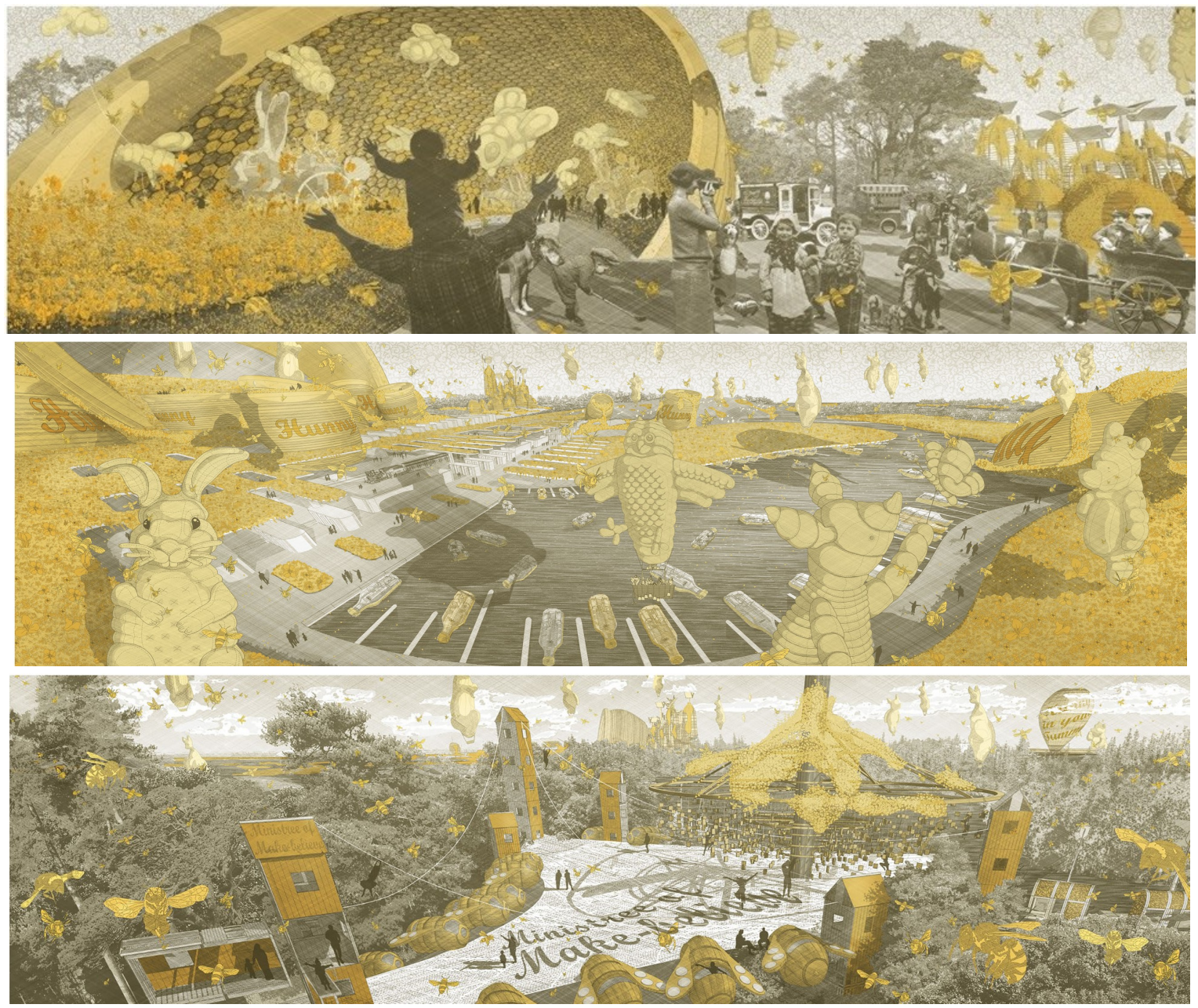

Gambar 2. The Bartlett 2014, Nick Elias, Unit 10.

Sumber :

https://www.google.co.id/search?q=diagram+architecture \&biw=1855\&bih=922\&source=1nms\&tbm=isch\&sa=X\&s $\mathrm{qi}=2 \& v e d=0$ ahUKEwjK5ojCu_RAhXI15QKHWNnAvUQ_AUIBigB\#tbm=isch\&q=drawing + bartlett\&imgrc $=\mathrm{i} 7 \mathrm{w}$ 2ePn6512jYM:

\section{LANDASAN TEORI}

Kerangka pikir didasari oleh penelusuran kembali jargon diagram dan arsitektur melalui tinjauan etimologi, melalui sebuah mode (trend) global yang mempertanyakan masalah penggambaran arsitektural, pemikiran kembali dengan menggali akar kata memberikan rekam jejak pemalihan penggunaan diagram sebagai gambar arsitektural, mengurai makna sekaligus membangun kembali argumentasi melalui teori-teori arsitektural, memaknai dasar pemikiran untuk direkonstruksi. Landasan Teori Pai (2002) dan Allen (1999) memberikan landasan teori bahwa inti dan anasir fundamental arsitektur berupa titik, garis adalah bahasa ruang paling murni, ia perlu dituangkan dalam kesederhanaan dan kejujuran yakni melalui diagram. Sebagai kontras, Einsenman (1999), Pyo (2011) dan Pyo (2012) berada di kutub berseberangan yang menampilkan diagram sebagai bahasa matematika grafis, dikerjakan secara digital dengan rona grafis tentu dalam lapisan-lapisan yang membentuk jalinan dalam jejaring matriks nan kompleks. Teori lain disejajarkan untuk mendukung pemikiran kembali tentang diagram sebagai gambar arsitektur yang ideal, dan kemudian dihadapkan dengan konteks jaman. 


\section{METODOLOGI}

Etimologi digunakan sebagai cara mempertanyakan kembali makna awal dari diagram arsitektur dan menampilkan pemalihan (transformation) termasuk evolusi diagram arsitektur sebagai media gambar arsitektural. Dengan metode kualitatif melalui kepustakaan, sebuah pemikiran konstruktivis diangkat untuk menjabarkan, menjelaskan, membuktikan termasuk menafsirkan kembali pemikiran fundamental mengenai diagram arsitektur. Metode kepustakaan membuka peluang membandingkan secara teori baik pemalihan maupun perluasan makna diagram arsitektur khususnya melalui situasi teraktual agar dapat dipertanyakan efektivitasnya. Penelitian ini dimulai dengan mengumpulkan permasalahan penggambaran arsitektur melalui kepustakaan, menyusun struktur argumen dengan menghubungkan teori-teori diagram, dilanjutkan dengan menampilkan kembali esensi kata dan etimologi melalui kamus bahasa dan kamus arsitektural. Mendefinisikan ulang dengan merekonstruksi teori-teori mengenai diagram menampilkan masalah, meluruskan dan memberikan alternatif solusi gambaran diagram yang seharusnya dikembangkan untuk masa depan.

\section{PEMBAHASAN}

Diagram sebagai informasi berbentuk grafis melahirkan pemahaman sekaligus menjembatani interaksi antara ruang dan waktu berdasar atas pertukaran keberagaman kondisi, anasir sosial, perkotaan termasuk konteks teritori tertentu (Pyo, 2011). Pemindahan informasi grafik berbasis gambaran visual menjadi sebuah proyeksi pada pemetaan mental kita, berpeluang untuk menunjukkan tingkat kestablilan, kedinamisan, multidimensi dari interpretasi yang beragam sebagai sebuah jalur lintasan sintesis ataupun sebaliknya. Sesederhana apapun sebuah diagram berpotensi untuk menjadi sebuah pemadatan informasi, seraya mengandung sistem pemikiran, lepas dari kemungkinannya melenceng untuk menjadi sekedar ekspresi seni bebas yang bersifat subjektif (Pyo, 2012). Logika ini menghantar kita kepada sebuah pengertian bahwa diagram memiliki kemampuan ganda atau lebih untuk mempengaruhi pikiran seseorang entah sebagai sebuah abstraksi, proses, simulasi grafis yang sarat informasi (Graf, 2007). Diagram menunjukkan keterhubungan dan jejaring logis melalui representasi simbol dan kode-kode grafis baik antara aktivitas, bentuk, organisasi maupun struktur skematis (Einsenman, 1999). Allen (1999) menegaskan peran diagram bukan sekedar sebagai media, namun juga sebagai alat pemindah, sebuah mesin proyeksi dalam proses analisa dan sintesa seseorang. Kompleksitas ini memperlihatkan diagram sebagai kumpulan kode, pola, skema dan aliran berbasis matrik keterhubungan titik dan garis menjadi jejaring kompleks. 


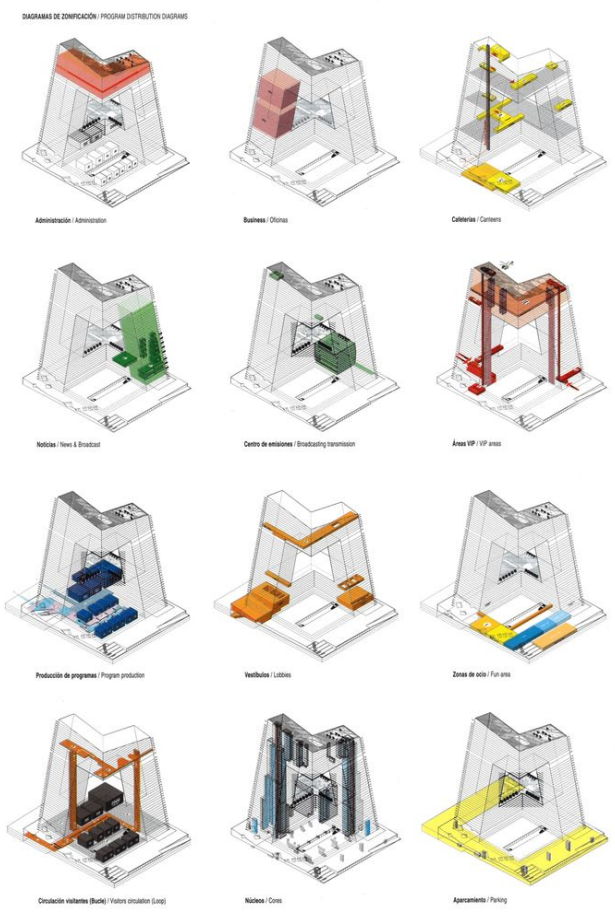

Gambar 3. CCTV Diagram, OMA

Sumber : https://s-media-cacheak0.pinimg.com/originals/18/d0/86/18d0860b9591c8445f54f830f9b3af45.jpg

Kemampuan diagram dalam mengekstraksi sekaligus menjembatani proses pengembangan, membuktikan bahwa kode - kode dan pemolaan dalam diagram menyimpan berbagai variasi genetik sebuah objek, dengan kemampuan generatif melahirkan sebuah proyeksi (Pyo, 2011). Pemahaman ini memunculkan paradigma kontradiktif, baik sebagai sebuah cara memurnikan dan mensterilkan makna sebuah objek sekaligus fungsi katalis untuk mengembangkan dan memperluas arti sebuah objek (Dulić, 2016). Kemampuan kontradiktif ini dipercaya membutuhkan kendali (control) dimana kemampuan diagram perlu dinegosiasi dan diseimbangkan oleh penciptanya (Einsenman, 1999). Kontrol ini yang mencegah celah ekspresi bebas dan signature bersifat seni. Memang benar adanya, seorang perancang perlu mampu menunjukkan cara pandang, cara pikir dan gaya dalam membuat objek arsitektural melalui pengejawantahan diagram, namun demikian kontrol dalam penggambaran akan mengantisipasi kemungkinan terjatuh pada ekspresi bebas dan kecenderungan abstrak yang tanpa sadar membuka kesempatan tidak jujur dalam penggambaran baik melalui memanipulasi tampilan visual atau sekedar menutupi sebuah kecacatan demi kepentingan lain. Sangatlah penting bagi seorang perancang untuk berkonsentrasi pada bentukan esensial meskipun perlu jua menjabarkan seluas-luasnya kompleksitas sebuah objek di saat bersamaan dan mengedepankan hal-hal fundamental pada aspek pembuatan diagram (Pai, 2002). Layaknya seorang perancang menghindari dekorasi dan tambahan yang tidak berdasar kepada parameter asli, sehingga perlu berusaha mendekati kepresisian seraya mengurangi bias., penjabaran ini menyadarkan kita bahwa diagram bukan saja dapat digunakan sebagai abstraksi esensial, tapi jua berpotensi sebagai media sintetik yang disalah gunakan (baik dengan sengaja atau tidak sengaja) sebagai trik seorang perancang dalam membuat ilusi visual. 
Teknik membuat diagram menuai dilema, kini berada dipersimpangan, ditengah-tengah arus komersialisasi dan komodifikasi arsitektur dalam melahirkan informasi visual representatif, arsitektur diproyeksikan bahkan secara nyata melalui diagram visualisasi. Tuntutan kompetisi melahirkan paradigma bahwa diagram perlu menjadi kompleks, sebuah bahasa grafis yang dilahirkan melalui instrumen berupa perangkat lunak, sehingga mampu memultiplikasi, menghasilkan layer-layer multidimensional dan terhubung dengan dunia maya melalui proses digital ke dalam dunia virtual (Garcia, 2010). Komputer singkatnya menjadi alat untuk memudahkan kita dalam memultiplikasi, mengkoneksi, mempresisikan artikulasi matrik ruang berdasarkan parameter-parameter yang dikendalikan oleh operator. Diagram telah ditransformasikan menjadi bentukan kompleks, lompat dari penggambaran dua dimensi menjadi tiga dimensi, terkoneksi lintas batas antara ruang nyata dan virtual dalam membangun dunia virtual reality, lebih jauh lagi diagram telah menjadi informasi global yang bisa diakses di segala penjuru dunia hanya dengan sentuhan jari. Kebebasan tanpa batas ini menempatkan diagram menjadi layaknya barang dagangan atau bahkan donasi, dengan mudah diunduh bahkan secara cuma-cuma, direka ulang dan ditempatkan dengan kemasan baru dengan keamanan dan jaminan yang tidak cukup layak bagi mereka yang memiliki hak cipta. Kemudahan replikasi, multiplikasi dan rekayasa kode-kode dalam penggambaran diagram dalam kenyataan memutarbalikkan diagram menjadi gambar-gambar visual rekaan yang seakan-akan nampak nyata, benar dan bernalar logika, bahkan menjadi perwakilan lain ruang cerminan. Teknik dan logika pembuatan sebuah diagram sangat tergantung kegunaan dan keperluan sebuah diagram untuk disajikan kepada khalayak (Pai, 2002). Diagram seharusnya menjadi alat jujur untuk menerangkan sebuah objek arsitektur, namun demikian diagram seringkali dijadikan sebuah camouflage untuk menempatkan gambar arsitektur menjadi seolah-olah presisi dan representatif meski hanya sebuah ilusi optik.

\section{KESIMPULAN DAN SARAN}

Diagram di ranah arsitektur telah dan terus berkembang untuk menjadi media segera (instant) yang lugas dalam menerangkan makna yang kompleks akan ruang. Tuntutan jaman menempatkan pengembangan diagram sederhana menjadi sebuah elaborasi yang kerapkali menitik beratkan pada dekorasi daripada kepentingan bentukan dan kerangka struktural. Diagram arsitektur adalah alat kerja bukan sekedar representasi visual. Solusi pengembangan diagram arsitektur dengan kembali ke akar, membawa pentingnya menempatkan penggambaran arsitektur kembali ke jalur yang benar secara tepat guna. Dengan mengedepankan kesederhanaan dan kejujuran diagram dengan membuatnya menjadi presisi dan minimal, dengan bantuan teknologi agar berkembang secara paralel untuk menjadi kompleks dan kaya. Untuk sementara, pandangan ini menjadi alternatif panduan ideal meski percobaan dengan cara pikir yang terbuka terhadap pembaharuan perlu terus digalakkan dalam pengembangan diagram arsitektur.

\section{REFERENSI}

Allen, S. (1999). Points and Lines: Diagrams and Projects for the City. Princeton Architectural Press. New York.

Eisenman, P. (1999). Diagram Diaries. Thames and Hudson. London.

Dulić, O \& Aladžić, V. (2016). “ A Note on Graphical Representations in Architecture Diagrams over Sketches. 4th International Conference: Contemporary Achievements in Civil Engineering. Subotica, Serbia. 22 April 2016. 835-844.

Garcia, M (2010). The Diagram of Architecture: AD Reader. Wiley. New York.

Graf, D. (2007). Diagrams. JSTOR Perspecta, Vol.22, Paradigms of Architecture (1986).42-71. 
Vol. 1, No. 1, April 2017: hlm 11-17

Onions, C.T. \& Friedrichsen, G.W.S. (1966). The Oxford Dictionary of English Etymology. Oxford University Press. Oxford.

Pai, H. (1993). From the Portfolio to the Diagram: Architectural Discourse and the Transformation of the Discipline of Architecture in America, 1918-1943. MIT Thesis. Massachusetts.

Pai, H. (2002). The Portfolio and the Diagram: Architecture, Discourse, and Modernity in America. The MIT Press. Cambridge.

Pyo, S., K. (2011). Program Diagram. DAMDI. Seoul.

Pyo, M. (2012). Conceptual and Activity Diagrams. RHED Publishers. Singapore.

Stevenson, A. (2010).Oxford Dictionary of English (3ed.). Oxford University Press. Oxford. 